\title{
AMPK Hyper-Activation Alters Fatty Acids Metabolism and Impairs Invasiveness of Trophoblasts in Preeclampsia
}

\author{
Xiaotao Yang ${ }^{a, b, c, c}$ Ping X $u^{a, b, c} \quad$ Fumei Zhang ${ }^{a, b, c} \quad$ Li Zhang ${ }^{a, b, c, d} \quad$ Yangxi Zheng ${ }^{a, b, c}$ \\ Mingyu Hu ${ }^{a, b, c}$ Lulu Wang ${ }^{a, b, c}$ Ting-li Han ${ }^{b, c, e} \quad$ Chuan Peng ${ }^{b, c}$ Lianlian Wang ${ }^{a, b, c, f}$ \\ Li Wen ${ }^{a, b, c}$ Yiwen Zenga, Rufei Gao ${ }^{\mathrm{b}, \mathrm{g}}$ Yong Xia ${ }^{\mathrm{h}}$ Chao Tong ${ }^{\mathrm{a}, \mathrm{b}, \mathrm{c}} \quad$ Zhu Yang ${ }^{\mathrm{b}, \mathrm{i}}$ \\ Hongbo Qja,b,c Philip N. Baker ${ }^{b, j}$
}

\begin{abstract}
aDepartment of Obstetrics, The First Affiliated Hospital of Chongqing Medical University, Chongqing, 'DInternational Joint Laboratory of Reproduction and Development, Ministry of Education of China, Chongqing Medical University, Chongqing, 'State Key Laboratory of Maternal and Fetal Medicine of Chongqing Municipality, Chongqing, dDepartment of Gynaecology and Obstetrics, Institute of Surgery Research, Daping Hospital, Third Military Medical University, Chongqing, China, 'Liggins Institute, University of Auckland, Auckland, New Zealand, fDepartment of Reproduction Health and Infertility, The First Affiliated Hospital of Chongqing Medical University. Chongqing, ILaboratory of Reproductive Biology, School of Public Health and Management, Chongqing Medical University, Chongqing, China, hDavis Heart and Lung Research Institute, Division of Cardiovascular Medicine, Department of Molecular and Cellular Biochemistry, The Ohio State University College of Medicine, Columbus, USA, 'Department of Obstetrics and Gynecology, The Second Affiliated Hospital of Chongqing Medical

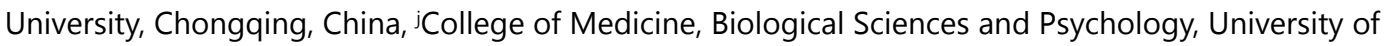
Leicester, Leicester, United Kingdom
\end{abstract}

\section{Key Words}

Preeclampsia $•$ AMPK $・$ Placenta $・$ Fatty acids $・$ Trophoblast $\bullet$ Metabolomics

\begin{abstract}
Background/Aims: Preeclampsia (PE) has long been assumed to be an ischemic disease of the placenta, although there is limited evidence as to how the ischemia impacts on the placenta. AMP-activated protein kinase (AMPK) is a key regulator of cellular energy metabolism and plays an important role in a variety of ischemic diseases by enhancing energy production. The present study investigated placental metabolism in PE, and the role of AMPK in regulating trophoblast function. Methods: placentas from normal and PE complicated pregnancies were subjected to GC-MS to identify fatty acids (FA) metabolic fingerprints, and total FA oxidation was assessed by malondialdehyde (MDA) measurement. The AMPK-ACC signaling pathway was assessed by q-PCR and Western Blotting. HTR8/SVneo trophoblast cultures were exposed to different oxygenation conditions to establish an in vitro PE cell model; further analysis by

X. Yang, P. Xu and F. Zhang contributed equally to this work.

\begin{tabular}{ll}
\hline Dr. Chao Tong, & Department of Obstetrics, The First Affiliated Hospital of Chongqing Medical University \\
Dr. Zhu Yang & 1 Youyi Road, Yuzhong District, Chongqing 400016 (China); Tel. +86 23 89011101 \\
and Dr. Hongbo Qi & Fax +86 23 89011102, E-Mail chaotongcqmu@163.com; cqyangz@vip.163.com; qihongbo728@163.com
\end{tabular}
\end{abstract}




\section{Cellular Physiology Cell Physiol Biochem 2018;49:578-594 \\ \begin{tabular}{l|l|l} 
DOI: 10.1159/000492995 & $\begin{array}{l}\text { O } 2018 \text { The Author(s). Published by S. Karger AG, Basel } \\
\text { www.karger.com/cpb }\end{array}$
\end{tabular} \\ Yang et al.: AMPK Regulates Trophoblasts Metabolism and Invasion}

GC-MS for metabolite profiling was then undertaken. Trophoblasts invasion was assessed by a matrigel transwell assay in the presence/absence of AMPK expression and after manipulations of AMPK activity, and then further validated by human villi outgrowth experiments. Results: AMPK phosphorylation and MDA production were significantly elevated in placentas from pregnancies complicated by PE. Metabolism of cis double bond FA was inhibited while trans double bond FA metabolism was promoted in PE placentas. HTR8/SVneo cell culture conditions of persistent low oxygenation mimicked the hyper-activation of AMPK and enhanced the FA oxidation that was observed in PE. AMPK activation impaired trophoblast invasion, while AMPK inhibition promoted trophoblast invasion. Conclusion: PE complicated placentas are associated with AMPK hyper-activation and consequent alterations in FA oxidation, which inhibit trophoblast invasion.

(C) 2018 The Author(s)

Published by S. Karger AG, Basel

\section{Introduction}

Hypertensive disorders complicate $5-10 \%$ of all pregnancies [1] and are a significant cause of maternal mortality; of these disorders, preeclampsia (PE) has the greatest influence on both mother and fetus [2]. PE occurs during pregnancy or in the early postpartum period, and is defined as newly diagnosed hypertension (a systolic blood pressure greater than 140 $\mathrm{mmHg}$ or a diastolic blood pressure greater than $90 \mathrm{mmHg}$ ) and substantial proteinuria (greater than or equal to $300 \mathrm{mg}$ in $24 \mathrm{~h}$ ) at or after 20 weeks of gestation [3]. More than 50, 000 maternal deaths are caused by PE annually [4], and none of the current therapies are curative; indeed, the only cure is to deliver the fetus and placenta (at premature gestations, this follows corticosteroids administration for promotion of fetal lung maturity [5]).

The placenta is an invasive pseudotumor-like organ; the penetrative nature of trophoblast cells invading the uterine endometrium mimics a highly invasive tumor. However, one of the key pathological manifestations of PE is a restricted invasion of trophoblast cells [6-8]. The rapid growth of tumor cells depends on a sustained energy supply, as highlighted by Luo et al.'s demonstration of the role of lipid metabolism in tumor invasion [9]; the impairment of trophoblasts invasion in PE placenta may thus be consequent on a compromised energy supply. Pertinently, Yan et al. reported that fatty acid binding protein (FABP) expression was increased in placentas from women with PE and that silencing FABP decreased trophoblasts proliferation, migration and invasion [10]. Moreover, fatty acids (FA) composition has been shown to differ in synctiotrophoblasts and cytotrophoblasts [11]; this can be attributed to the different energy demands during differentiation, and implies that dysregulation of energy production from FA metabolism might be one of the underlying mechanisms of impaired trophoblast invasion in PE.

AMP-activated protein kinase (AMPK) is a highly conserved, multi-substrate serine/ threonine protein kinase involved in the regulation of cellular and whole organ metabolism [12]. Hypoxia, starvation, and exercise can activate AMPK by elevating the AMP/ATP ratio [13], and AMPK is the master switch of glucose and lipid metabolism. Recent studies have shown that AMPK determines spermatozoa quality and function through a dependence of proliferation and motility on energy levels [14]. Moreover, in a variety of ischemic diseases, such as ischemic heart disease, cerebral ischemia, and renal ischemia, AMPK is activated and metabolism of glucose and FA is enhanced [15-17]. Although PE has been long assumed to be an ischemic disease of placenta, the role of AMPK on the biological functions of trophoblast cells in PE remains unknown.

In this study, we identified differences in the FA metabolome between placentas from PE and normal pregnancies, and we investigated the regulatory effects of AMPK on trophoblast cell invasion. 


\section{Cellular Physiology Cell Physiol Biochem 2018;49:578-594 \begin{tabular}{ll|l} 
and Biochemistry Published online: 29 August, 2018 & $\begin{array}{l}\text { (c) } 2018 \text { The Author(s). Published by S. Karger AG, Basel } \\
\text { www.karger.com/cpb }\end{array}$ \\
\hline
\end{tabular}}

Yang et al.: AMPK Regulates Trophoblasts Metabolism and Invasion

\section{Materials and Methods}

\section{Human placenta samples}

Human placental tissue samples were collected as described previously [18]. Samples were obtained from nulliparous subjects admitted to the department of Obstetrics in the First Affiliated Hospital of Chongqing Medical University. 16 women had uncomplicated term pregnancies and the pregnancies of 16 women were complicated by PE. All subjects underwent elective caesarean section. All subjects gave informed written consent and ethical permission was obtained from the Ethics Committee of Chongqing Medical University. Placentas were sampled immediately after delivery; ten pieces of placental tissue from each subject were taken randomly. All placental tissue was quickly rinsed in $0.9 \%$ sterile ice-cold normal saline (NS) twice, then snap-frozen in liquid nitrogen and stored at $-80^{\circ} \mathrm{C}$ for further use.

\section{Cell line}

HTR8/SVneo cells were kindly provided by Dr. Charles Graham (Queen's University, Kingston, Ontario, Canada), and maintained in RPMI1640 medium (Gibco, USA) supplemented by $10 \%$ fetal bovine serum (FBS, PAN-Biotech, Germany), 100U/mL penicillin and 100ug/mL streptomycin (Beyotime, Shanghai, China).

\section{MDA Measurement}

Malondialdehyde (MDA) levels in placenta homogenates were determined spectrophotometrically by using the Lipid Peroxidation MDA Assay Kit (Beyotime Biotechnology, Shanghai, China)[19]. Briefly, 50 mg placental tissue was placed into $500 \mu \mathrm{l}$ RIPA lysis buffer (Beyotime Biotechnology, Shanghai, China) and homogenized, then centrifuged at $4{ }^{\circ} \mathrm{C} 1600 \mathrm{~g}$ for $10 \mathrm{~min}$. The supernatants were then extracted and the protein concentration determined. $200 \mu \mathrm{l}$ primary solution was removed into MDA working reagent, heated at $100{ }^{\circ} \mathrm{C}$ for $15 \mathrm{~min}$, and then centrifuged at room temperature $1000 \mathrm{~g}$ for $10 \mathrm{~min}$. $200 \mu \mathrm{l}$ supernatants were added into a 96 well plate to determine spectrophotometry at a $532 \mathrm{~nm}$ wavelength. MDA levels in HTR8/SVneo cells were determined as previously reported [20]. After treatment, HTR8/SVneo cells were harvested, washed with cold PBS and dissociated using trypsin. The cell suspension was centrifuged for 5 min at $1000 \times$ g and $1 \times 10^{6}$ cells were resuspended in 150-250 $\mu$ l pre-cooled PBS. The freeze-thaw process was repeated several times until the cells were fully lysed. After centrifugation for $10 \mathrm{~min}$ at $1500 \times \mathrm{g}$ at $4^{\circ} \mathrm{C}$, the supernatant was collected for assay using a MDA ELISA kit (Elabscience, China) according to the manufacturer's instructions.

\section{ATP measurement}

$10 \mathrm{mg}$ of human term placenta tissue was homogenized using a Dounce homogenizer, and then centrifuged for 5 minutes at $4^{\circ} \mathrm{C}$ at $13,000 \mathrm{~g}$. The supernatant was collected for ATP measurement by the use of an ATP assay kit (Abcam, USA) according to the manufacturer's instructions; fluorescence at an excitation wavelength of $535 \mathrm{~nm}$ and at an emission wavelength of $587 \mathrm{~nm}$ was determined by a spectrophotometer (Thermo fisher, Finland).

\section{ROS measurement}

HTR8/SVneo cells were seeded in 96-well plates, cultured to 70\% confluence, and then treated with DMS0, 1\% oxygen, 200 $\mu \mathrm{M}$ AICAR (5-aminoimidazole-4-carboxamide-1-beta -4-ribofuranoside), $20 \mu \mathrm{M}$ Compound C, $25 \mu \mathrm{M}$ etomoxir or AICAR with etomoxir, respectively for $24 \mathrm{hrs}$. After treatment, cells were washed three times with PBS and incubated with 2, 7-Dichlorodi-hydrofluorescein diacetate (DCFH-DA) at $37^{\circ} \mathrm{C}$ for $20 \mathrm{~min}$. Then DCFH fluorescence distribution at an excitation wavelength of $488 \mathrm{~nm}$ and at an emission wavelength of $525 \mathrm{~nm}$ was detected by a spectrophotometer (Thermo fisher, Finland).

\section{Primary human trophoblast isolation}

Primary human trophoblast (PHT) cells were isolated from human term placenta as previously described [21]. Briefly, immediately after delivery, placenta tissue was cut into $2 \mathrm{~mm}^{3}$ segments, and the connective tissue and blood clot were removed. 625mg dispase II (Roche, Swiss) and 400 $\mu$ l DNase (Roche, Swiss) were added in succession, for 1 hours and 15 minutes respectively at $37{ }^{\circ} \mathrm{C}$, to digest the placenta tissue. The resulting suspension was then filtered $(70 \mu \mathrm{m}$, Solarbio, Shanghai, China) and centrifuged at $300 \mathrm{~g}$ for 7 minutes; the precipitate was resuspended in $40 \mathrm{ml}$ platelet lysing solution (Gibco, USA) and washed 


\section{Cellular Physiology Cell Physiol Biochem 2018;49:578-594 and Biochemistry \begin{tabular}{l|l} 
DOI: 10.1159/000492995 & $\begin{array}{l}\text { C } 2018 \text { The Author(s). Published by S. Karger AG, Basel } \\
\text { www.karger.com/cpb }\end{array}$
\end{tabular}

twice using DMEM/F12 (Gibco, USA) that was supplemented with $10 \%$ FBS (Gibco, USA). After filtration on two occasions, the suspension was added into a Percoll gradient $(60 \%, 50 \%, 40 \%$, $30 \%, 20 \%$ ) (Bio-Rad, USA), followed by centrifugation at $1000 \mathrm{~g}$ for 20 minutes. The $20-40 \%$ Percoll layer was collected and added into DMEM/F12 that contained 10\%FBS, and centrifuged at $300 \mathrm{~g}$ for 7 minutes; the pellet was resuspended in $10 \mathrm{ml}$ DMEM/F12 containing 10\% FBS and antibiotics, and then these cells were seeded into petri dishes $[22,23]$.

\section{siRNA transfection}

The siRNA transfection solutions (hs-AMPK $\alpha 1$ siRNA duplex, Control siRNA duplex, siRNA transfection medium, siRNA transfection reagent) were purchased from Shanghai GeneBio Co. Ltd (Shanghai GeneBio Co. Ltd, Shanghai, China). The siRNA transfection procedure was carried out as per the manufacturer's instructions. The siRNA sequence used is detailed in Table 1.

HTR-8/SVneo human trophoblast cells were plated into $10 \mathrm{~cm}$ petri dishes and allowed to grow to 70\%-80\% confluence in antibiotic-free normal growth medium supplemented with FBS. Then, solution A (siRNA duplex and siRNA transfection medium) and solution B (siRNA transfection reagent and transfection medium) were prepared as the manufacturer's instructions. A mixture of solution A and solution B was then added to the cells. After $24 \mathrm{~h}$ of incubation, the cells were prepared for further experiments.

\section{Western Blotting}

Western blotting was performed as previously described [21]. $100 \mathrm{mg}$ placental tissue was homogenized in $500 \mu \mathrm{l}$ RIPA buffer on ice. Homogenates were then centrifuged at $13000 \mathrm{~g}$ for $15 \mathrm{~min}$ at $4{ }^{\circ} \mathrm{C}$, and supernatants were collected for protein concentration measurement by the BCA protein quantification kit (Beyotime Biotechnology, Shanghai, China)[22]. $20 \mu \mathrm{g}$ total protein was subjected to $7 \%$ or $10 \%$ discontinuous SDS-PAGE and transferred to a PVDF membrane (Roche, UK). Membranes were blocked for 1 $\mathrm{h}$ with $5 \%$ non-fat dried milk in Tris-buffered saline containing $0.05 \%$ Tween-20 (TBST) and then probed with rabbit monoclonal antibodies to AMPK (\#2532, Cell Signaling Technology), p-AMPK (\#2535, Cell Signaling Technology), acetyl-CoA carboxylase (ACC) (\#3662, Cell Signaling Technology), p-ACC (\#3661, Cell Signaling Technology) or mouse monoclonal antibodies to $\beta$-actin (\#3700, Cell Signaling Technology) overnight at $4^{\circ} \mathrm{C}$. Membranes were then incubated with horseradish peroxidase-conjugated goat anti-mouse IgG or goat anti-rabbit IgG for $1 \mathrm{~h}$ at room temperature [23]. The bands were scanned and quantified by densitometry analysis using an image analyzer Quantity One System (Bio-Rad, Richmond, CA, USA).

\section{RT-qPCR}

The total RNA extraction and cDNA reverse transcription was performed as previously described [24]. Primers (Table 2) were synthesized by Invitrogen (Thermo Fisher Scientific Inc. Paisley, UK), mRNA levels were quantified by using SYBR Green I and melt curve analysis to ensure amplification specificity through Bio-Rad CFX Connect ${ }^{\mathrm{TM}}$ Real-Time System. Forty cycles of PCR were performed: initial enzyme activation and template denaturation at $95{ }^{\circ} \mathrm{C}$ for $10 \mathrm{~min}$ was followed by denaturation at $95^{\circ} \mathrm{C}$ for $10 \mathrm{~s}$, annealing at 63.8 ${ }^{\circ} \mathrm{C}$ for $30 \mathrm{~s}$, and an extension phase at $72{ }^{\circ} \mathrm{C}$ for $30 \mathrm{~s}$ followed by melt curve analysis. Ct values were used for quantification. All assays were 95-105\% efficient.

\section{Matrigel Transwell Assay}

The matrigel invasion assay in this study was performed as previously reported [25]. The invasion of HTR8 trophoblastic cells was measured in matrigel (Corning, NY, USA)-coated transwell inserts (8.0 $\mu \mathrm{m}$, Merck Millipore, Darmstadt, Germany) that contained polycarbonate filters with a pore size of $8.0 \mu \mathrm{m}$. The inserts were coated with $60 \mu \mathrm{l}$ matrigel matrix. After incubation at $37{ }^{\circ} \mathrm{C}$ for $4 \mathrm{~h}$ to gel, $4 \times 10^{4}$ siAMPK transfected or nontransfected HTR8/SVneo cells with or without AICAR (200 $\mu \mathrm{mol} / \mathrm{L}) /$ Compound C $(20$ 


\section{Cellular Physiology Cell Physiol Biochem 2018:49:578-594 \begin{tabular}{l|l|l} 
and Biochemistry & Published online: 29 August, 2018 & $\begin{array}{l}\text { C } 2018 \text { The Author(s). Published by S. Karger AG, Basel } \\
\text { www.karger.com/cpb }\end{array}$ \\
\hline
\end{tabular}}

Yang et al.: AMPK Regulates Trophoblasts Metabolism and Invasion

$\mu \mathrm{mol} / \mathrm{L}$ ) in $200 \mu \mathrm{l}$ RPMI Medium 1640 basic (1X) (Life technologies, WA, USA) were seeded in upper chamber on the top of the matrigel, while $500 \mu \mathrm{l}$ of medium with $10 \%$ FBS were added into the lower well. After culture in $21 \% \mathrm{O}_{2}$ or $1 \% \mathrm{O}_{2}$ at $37^{\circ} \mathrm{C}$ for $24 \mathrm{~h}$, the non-invaded cells on the top of the inserts were scraped off using a cotton swab. The filter under the inserts, with attached invaded cells, was washed with cold PBS, and then fixed in methanol followed by 10 min of drying, and then stained with $0.1 \%$ hexamethylpararosaniline. The HTR8/SVneo cells in the inserts were counted through an EVOS FL Auto microscope (Life technologies, WA, USA) at a magnification of $200 \times$ in 10 random fields.

\section{Gelatin Zymography}

The MMP2 activity was identified by a gelatin zymographic analysis kit according to the manufacturer's instructions (Genmed Scientifics Inc., MA, USA). $10 \mu \mathrm{l}$ of protein from the HTR8/SVneo cells was subjected to electrophoresis. The gels were washed in $100 \mathrm{ml}$ renaturation buffer for $60 \mathrm{~min}$ on the shaking platform at $50 \mathrm{rpm}$, and then incubated in digestive solution at $37{ }^{\circ} \mathrm{C}$ overnight on the shaking platform at $50 \mathrm{rpm}$. Gels were stained in $100 \mathrm{ml}$ staining buffer by protected from light at room temperature for $1 \mathrm{~h}$ on the shaking platform at $50 \mathrm{rpm}$, and then destained in $100 \mathrm{ml}$ destaining buffer. Finally, the gels were incubated in $50 \mathrm{ml}$ stop buffer and scanned by a Quantity One System (Bio-Rad, Richmond, CA, USA).

\section{Human placental sample preparation for Gas Chromatography-Mass Spectrometry (GC-MS)}

$50 \mathrm{mg}$ sections of placental tissue were weighed and then placed into an Eppendorf tube; $500 \mu \mathrm{l}$ prechilled methanol-water $(1: 1)$ and $20 \mu \mathrm{l}$ of $\mathrm{D}_{4}$-alanine were then added. The sample mixture was centrifuged at $10000 \mathrm{~g}$ for $10 \mathrm{~min}$ at $4{ }^{\circ} \mathrm{C}$ after homogenization for $30 \mathrm{~s}$; the supernatant was then transferred to a new Eppendorf tube. $500 \mu \mathrm{l}$ of pre-chilled chloroform/methanol (3:1) was then added to the tissue pellet and homogenized for $30 \mathrm{~s}$; the mixture was centrifuged at $10000 \mathrm{~g}$ for $10 \mathrm{~min}$ at $4{ }^{\circ} \mathrm{C}$, and the supernatant was collected into the same Eppendorf tube. The organic extract was dried in a speedVac for 4 hours and then stored at $-80{ }^{\circ} \mathrm{C}[26]$.

\section{HTR8/SVneo trophoblast cell sample preparation for GC-MS}

The HTR8/SVneo trophoblast cells were exposed to $21 \% \mathrm{O}_{2}$ or $1 \% \mathrm{O}_{2}$ for 24 hours. The cells were washed with $10 \mathrm{ml} 37^{\circ} \mathrm{C}$ deionized water (PBS) to the cell surface, $10 \mathrm{ml}$ of liquid nitrogen was then added to the dish to terminate the cell metabolism. $1.2 \mathrm{ml}$ of cold 9:1 (methanol: chloroform) (including $20 \mu \mathrm{l}$ of internal standard: $\mathrm{D}_{4}$-alanine) was added into each plate. Cells were scraped with a cell lifter and the extracts were transferred to $1.5 \mathrm{ml}$ Eppendorf tube and vortexed for $30 \mathrm{~s}$. Cells were then pelleted at $4^{\circ} \mathrm{C}$ degree for $15 \mathrm{~min}$ at $17000 \mathrm{~g}$; the supernatant was transferred into a new Eppendorf tube and the liquid dried by speedVac for 4 hours prior to storage at $-80^{\circ} \mathrm{C}$ [27].

\section{Derivatization}

The freeze-dried samples were resuspended in $200 \mu \mathrm{l}$ of sodium hydroxide $(\mathrm{NaOH}, 1 \mathrm{~mol} / \mathrm{L})$, vortexed for $20 \mathrm{~s}$, and then transferred into glass tubes. $167 \mu \mathrm{l}$ of methanol and $34 \mu \mathrm{l}$ of pyridine were added into the glass tube in order, then $20 \mu \mathrm{l}$ of MCF was added and vortexed immediately for $30 \mathrm{~s}$; another $20 \mu \mathrm{l}$ of MCF was added and vortexed for 30 s. $400 \mu \mathrm{l}$ chloroform was then added to the samples prior to a gentle vortex for $10 \mathrm{~s} ; 400 \mu \mathrm{l}$ of sodium bicarbonate $(50 \mathrm{mmol} / \mathrm{L})$ was added and vortexed for $10 \mathrm{~s}$. The samples were then centrifuged at $1500 \mathrm{rpm}$ for $5 \mathrm{~min}$ to separate the mixture into the upper aqueous layer and lower organic layer. The upper aqueous layer was discarded and the remaining water was removed by adding sodium sulfate; the organic layer was transferred into a GC-MS sample vial for analysis [28].

\section{GC-MS conditions and instrumentation}

The MCF derivatives were detected in an Agilent Technology GC system (7890B, Agilent Technology, California, USA) coupled to a MSD mass selective detector (EI) (5977A, Agilent Technology, California, USA) setting at $70 \mathrm{eV}$. The gas column for all tests was a ZB-1701 GC capillary column $(0.15 \mu \mathrm{m} \times 250 \mu \mathrm{m}$ id x 30 $\mathrm{m}$ with $5 \mathrm{~m}$ guard column, Phenomenex). The parameters were referenced from Smart [28]. Samples were injected with the injector temperature at $290^{\circ} \mathrm{C}$ under pulsed splitless mode. A constant flow of $1 \mathrm{~mL} / \mathrm{min}$ of helium gas flow was set through the GC-column. The GC-oven temperature was originally held at $45^{\circ} \mathrm{C}$ for $2 \mathrm{~min}$, then with a gradient ascent of $9^{\circ} \mathrm{C} / \mathrm{min}$ to $180^{\circ} \mathrm{C}$; after $5 \mathrm{~min}$ the temperature was increased at 40 ${ }^{\circ} \mathrm{C} / \mathrm{min}$ to $220^{\circ} \mathrm{C}$. After another $5 \mathrm{~min}$, the temperature was increased with a gradient of $40{ }^{\circ} \mathrm{C} / \mathrm{min}$ to 240 


\section{Cellular Physiology Cell Physiol Biochem 2018;49:578-594 \begin{tabular}{l|l|l} 
DOI: 10.1159/000492995 & $\begin{array}{l}\text { O } 2018 \text { The Author(s). Published by S. Karger AG, Basel } \\
\text { wwww.karger.com/cpb }\end{array}$
\end{tabular}

${ }^{\circ} \mathrm{C}$ for $11.5 \mathrm{~min}$; ultimately, the temperature was increased $40{ }^{\circ} \mathrm{C} / \mathrm{min}$ until it reached $280^{\circ} \mathrm{C}$ and it remained at $280{ }^{\circ} \mathrm{C}$ for $2 \mathrm{~min}$. The quadrupole temperature was set at $230{ }^{\circ} \mathrm{C}$ and the interface temperature was $230{ }^{\circ} \mathrm{C}$. The mass spectrometry was worked in scan mode and began after $5.5 \mathrm{~min}$ with scan time of $0.1 \mathrm{~s}$ of mass range between 38$550 \mathrm{amu}$.

\section{Statistical analysis}

All data are presented as means \pm SEM, and statistical significance was accepted when $\mathrm{P}<0.05$. Data that were not normally distributed were square root transformed before statistical analysis. Comparisons between the groups were made with a two-way between-subjects analysis of variance. Statistical calculations were made with GraphPad Prism version 5.00 for Windows (GraphPad Software, San Diego, CA).
Table 3. Characteristics of subjects. Values are means \pm SEM. Abbreviations: BMI, body mass index; SBP, systolic blood pressure; DBP, diastolic blood pressure. $\left({ }^{*} \mathrm{p}<0.05 ;{ }^{* *} \mathrm{P}<0.01 ;{ }^{* * *} \mathrm{p}<0.001\right)$

\begin{tabular}{lccc}
\hline Parameters & PE group (N=16) & Control group ( $=16)$ & P-value \\
\hline Mean age, years-old & $28.63 \pm 0.80$ & $29.19 \pm 0.80$ & 0.61 \\
BMI (pregestation) & $21.90 \pm 0.64$ & $20.99 \pm 0.71$ & 0.35 \\
BMI (prenatal) & $29.44 \pm 0.76$ & $27.77 \pm 0.85$ & 0.15 \\
Mean maximum SBP, mmHg & $155.5 \pm 1.83$ & $117.4 \pm 3.21$ & $<0.0001^{* * *}$ \\
Mean maximum DBP, mmHg & $100.1 \pm 3.209$ & $67.63 \pm 1.97$ & $<0.0001^{* * *}$ \\
Gestational age at delivery, weeks & $37 \pm 3.76$ & $39 \pm 0.83$ & $0.0002^{* * *}$ \\
Birth weight, g & $2748 \pm 130.0$ & $3229 \pm 81.44$ & $0.0031^{* *}$ \\
Placental weight, $\mathrm{g}$ & $478.0 \pm 11.43$ & $558.8 \pm 11.86$ & $<0.0001^{* * *}$ \\
Fetal gender (Male/Female) & $9 / 7$ & $6 / 10$ & \\
& & & $-0 \mathrm{mg}$ \\
& $\pm: 1 / 16$ & & $\pm 10-20 \mathrm{mg}$ \\
Proteinuria & $+: 6 / 16$ & $-: 10 / 16$ & $+30-70 \mathrm{mg}$ \\
& $++4 / 16$ & $\pm: 4 / 16$ & $++100-200 \mathrm{mg}$ \\
& $+++: 4 / 16$ & $+: 2 / 16$ & $+++300-600 \mathrm{mg}$ \\
& $++++1 / 16$ & & $++++0 \mathrm{VER}$ \\
\hline
\end{tabular}

\section{Results}

\section{Characteristics of subjects}

The subject characteristics are summarized in Table 3. Systolic and diastolic blood pressures in the PE group were higher than in the control group. The gestational age at delivery was significantly lower in the PE group; nearly half of the infants were prematurely delivered in PE pregnancies, but none of 16 women in the control group underwent preterm birth. The PE group had lower birth weights and lower placental weights.

\section{Fatty acid metabolism shift in PE placenta}

Term placentas from both groups were subjected to GC-MS analysis to determine the metabolomic fingerprints of the placenta in PE. On multivariate data analysis of all GC-MS features, Partial Least Squares-Discriminate Analysis (PLS-DA) revealed that the normal and PE placenta groups were clustered separately (Fig. 1A). A Z-score heat-map described 15 FA in PE placentas that differed from the normal placentas; 7 FA were down-regulated in PE placenta, including heneicosanoic acid, 11, 14-eicosadienoic acid, 11-trans-octadecenoic acid, tridecanoic acid, heptanoic acid, nonanoic acid and decanoic acid, while 8 FA were upregulated in PE placenta, including octadecanoic acid, 5, 8,11-cis-eicosatrienoic acid, cis-11, 14-eicosadienoic acid, 11, 14, 17-cis-eicosatrienoic acid, 9, 12,15-cis-octadecatrienoic acid, 8, 11, 14-cis-eicosatrienoic acid, hexadecanoic acid, and 7, 10, 13, 16, 19-cis-docosapentaenoic acid (Fig. 1B).

In summary, placental FA metabolism was dramatically altered in PE, as shown by not only retention of cis double bond FAs and reduction of trans double bond FAs, but also by decreases in medium chain FAs and an accumulation of long chain FAs.

\section{PE placenta is associated with hyper-activation of the AMPK-ACC pathway}

We examined the expression of AMPK in human placentas. mRNA levels of AMPK $\alpha 1$ transcript 1, AMPK $\alpha 1$ transcript 2 and AMPK $\alpha 2$ did not differ between normal and PE placentas (Fig. 2A); this was consistent with Western blotting of total AMPK (Fig. 2B). Intriguingly, AMPK phosphorylation was significantly increased in PE placentas compared to the normal group, indicating that PE was associated with AMPK hyper-activation. Consistent with this, the direct downstream effector of AMPK, ACC, was also significantly phosphorylated in PE placentas (Fig. 2C), while total protein levels remained similar between the two groups. Moreover, the end product of lipid peroxidation, MDA, was significantly accumulated in 
Fig. 1. The metabolome of placentas from normal and PE complicated pregnancies. A. Partial LeastSquares-Discriminate Analysis (PLS-DA) of fatty acids metabolism, PC1 vs. PC2 vs. PC3. The score plot separated PE placentas (blue) and normal placentas (red); B. The Z-score heat-map of significantly different fatty acids in normal and PE placentas. $p<0.05$, $\mathrm{FDR}<0.01, \mathrm{~N}=12$.

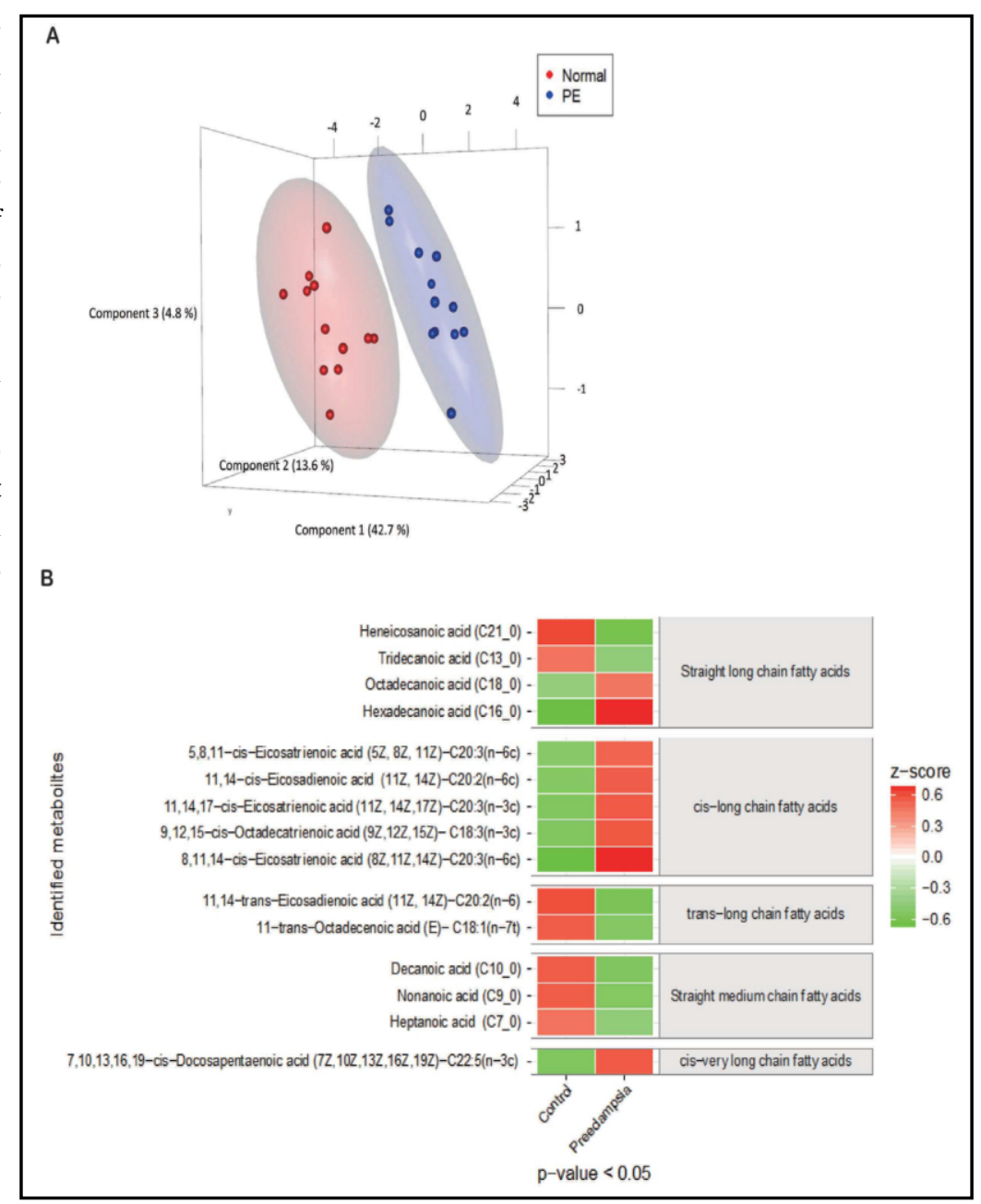

the PE placentas, as compared to the normal placentas (Fig. 2D). Additionally, to ascertain whether the signaling and metabolites alteration are coupled with energy production, we assessed ATP levels in normal and PE complicated placentas, and the results demonstrated that ATP levels were significantly higher in the PE group (Fig. 2E). Taken together, PE was associated with placental hyper-activation of the AMPK-ACC signaling pathway and consequent elevations in FA oxidation.

Persistent low oxygenation induced AMPKactivation and influenced fatty acids metabolism in HTR8/SVneo trophoblastic cells

Altered oxygenation of HTR8/SVneo trophoblast cell was induced by $1 \% \mathrm{O}_{2}$ or $\mathrm{CoCl}_{2}$ for different durations $(2 \mathrm{~h}, 6 \mathrm{~h}, 24 \mathrm{~h})$, AMPK phosphorylation levels were then measured to determine whether these conditions in HTR8/SVneo cells mimicked a 'PE like' metabolite profile.

$2 \mathrm{~h}$ or $6 \mathrm{~h}$ of $1 \% \mathrm{O}_{2}$ incubation conditions did not activate AMPK in HTR8/SVneo cells, however, $24 \mathrm{~h}$ of $1 \% \mathrm{O}_{2}$ incubation significantly elevated AMPK phosphorylation (Fig. 3A). Moreover, $100 \mu \mathrm{mol} / \mathrm{L} \mathrm{CoCl}_{2}$, an electron transport chain inhibitor, also elevated AMPK phosphorylation after 24 hours of treatment, although to a lesser extent than $1 \% \mathrm{O}_{2}$ incubation (Fig. 3B). This data suggested that the trophoblast was resistant to low oxygenation, and that persistent rather than acute hypoxia mimicked the hyper-activation of AMPK identified in PE placenta.

As with PE placentas, the MDA levels of 1\% oxygen-treated HTR8/SVneo cells were significantly increased (Fig. 3C), suggesting that trophoblast FA oxidation was promoted by 


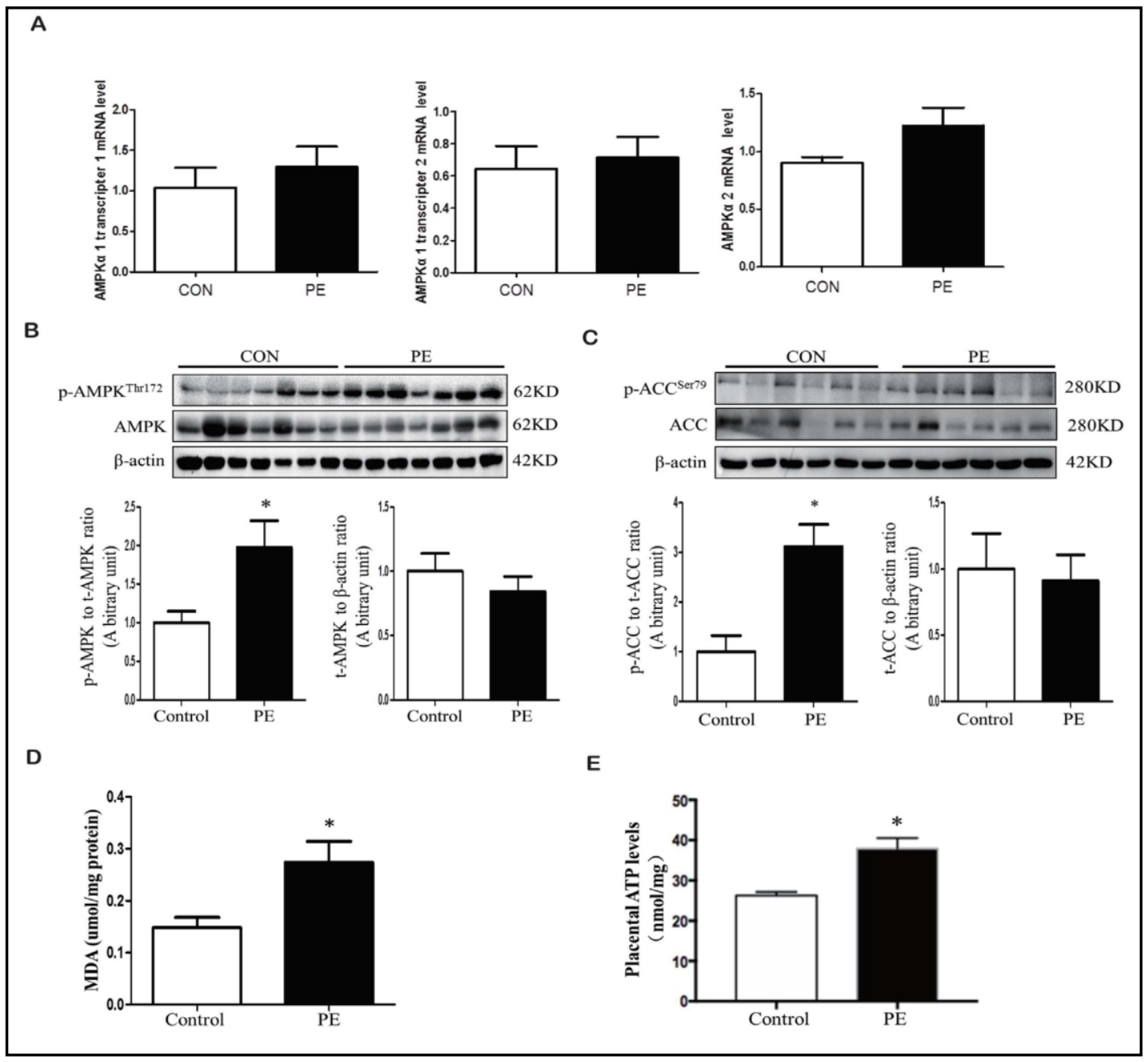

Fig. 2. AMPK-ACC signaling in human term placentas from normal and PE complicated pregnancies. A. AMPK mRNA expression levels detected by q-PCR; B. AMPK total protein expression and phosphorylated protein levels were measured by Western blotting; C. ACC total protein expression and phosphorylated protein levels were measured by Western blotting; D. MDA levels in PE and normal placentas, ${ }^{*} \mathrm{p}<0.05, \mathrm{~N}=16$; E. ATP levels in PE and normal placentas, ${ }^{*} \mathrm{p}<0.05, \mathrm{~N}=6$.

persistent low oxygen-induced AMPK activation. Consistent with this finding, when the cells were subjected to GC-MS and subsequent multivariate data analysis, Partial Least SquaresDiscriminate Analysis (PLS-DA) revealed that the different oxygenation conditions were clustered separately (Fig. 3D). Notably, in 1\% oxygenation, 32 of 36 differentially enriched FAs were significantly decreased compared to $21 \%$ oxygenation conditions (Fig. 3E), indicating an overall acceleration of FA metabolism. Interestingly, $1 \%$ oxygenation enhanced metabolism of both cis and trans double bond FAs in HTR8/SVneo cells. To further investigate the underlying mechanism of discrepancy in cis/trans double bond FA utilization between placenta and HTR8/SVneo, levels of the rate-limiting isomerase of cis double bond FA, 2, 4-dienoyl-CoA reductase (DECR1) were then determined. Placental DECR1 was significantly reduced in PE pregnancies compare to normal pregnancies (Fig. 4A). However, DECR1 expression was significantly higher in HTR8/SVneo cells than in primary human trophoblast (PHT), indicating that HTR8/SVneo cells have much higher capability of converting cis double bond FAs to trans double bond FAs, which can be further utilized in $\beta$-oxidation (Fig. 4B). 


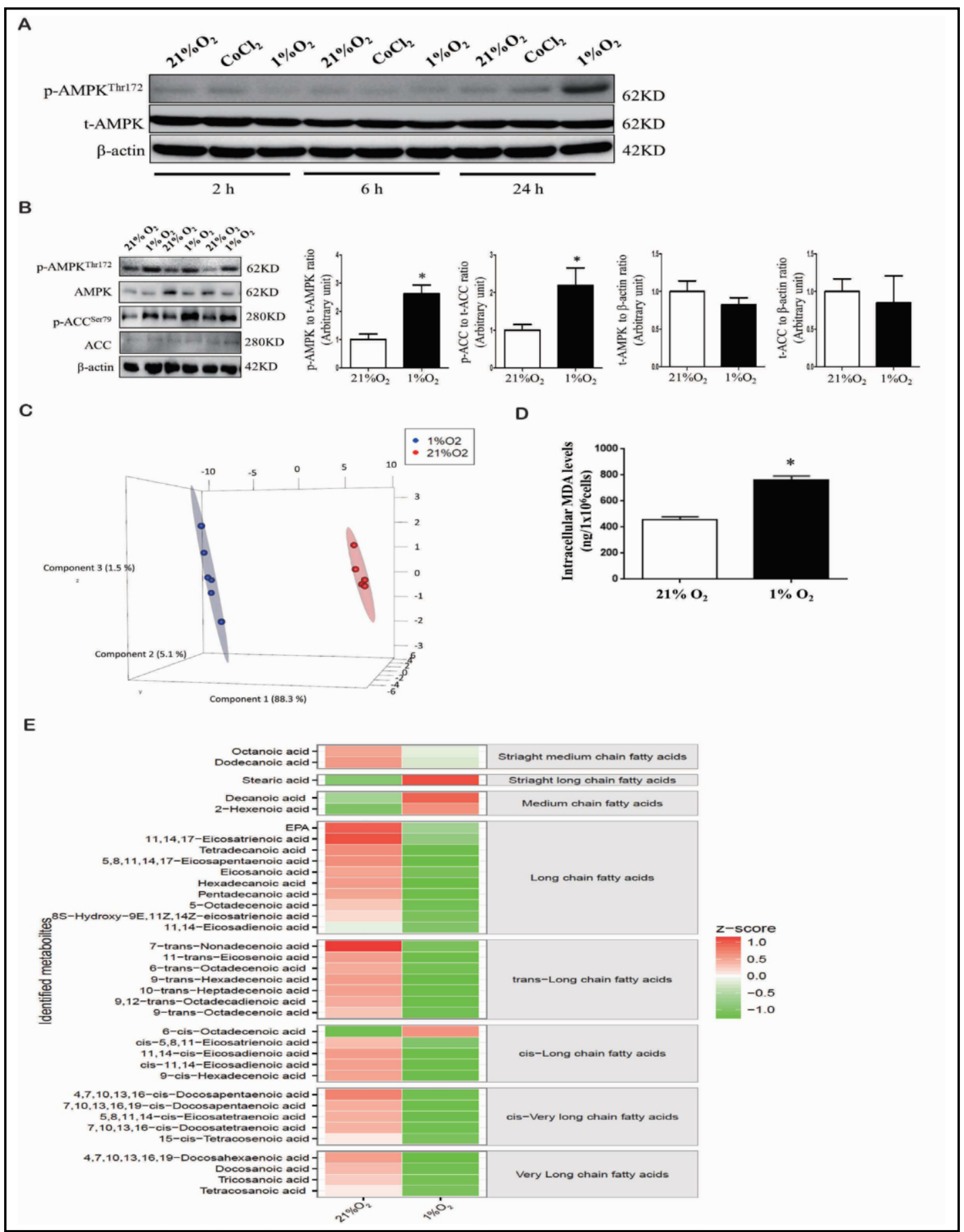

Fig. 3. Establishment of persistent hypoxia induced in vitro PE model. A. The activation of AMPK in HTR8/ SVneo cell after incubation in $21 \% \mathrm{O}_{2}, 1 \% \mathrm{O}_{2}$ or $100 \mu \mathrm{mol} / \mathrm{L} \mathrm{CoCl}_{2}$ for $2 \mathrm{~h}$, $6 \mathrm{~h}$ and $24 \mathrm{~h}$ respectively, ${ }^{*} \mathrm{p}<0.01$ vs. vehicle, ${ }^{*} \mathrm{p}<0.001$ vs. siRNA-NC, $\mathrm{N}=3$; B. AMPK- ACC signaling in HTR8/SVneo cell after $24 \mathrm{~h}$ of $21 \% \mathrm{O}_{2}$ or $1 \% \mathrm{O}_{2}$ incubation, $* \mathrm{p}<0.001$ vs. vehicle, $\# \mathrm{p}<0.001$ vs. control, $\mathrm{p}<0.001$ vs. siRNA-NC, $\mathrm{N}=3$; C. MDA levels in $21 \% \mathrm{O}_{2}$ and $1 \% \mathrm{O}_{2}$ treated HTR8/SVneo cells, ${ }^{*} \mathrm{p}<0.05, \mathrm{~N}=3$; D. PLS-DA of HTR8/SVneo cell metabolome in $21 \%$ and $1 \%$ oxygenation conditions; E. The profile of markedly altered metabolites between $21 \% \mathrm{O}_{2}$ and 1 $\% \mathrm{O}_{2}$ treated HTR8/SVneo cells, $\mathrm{p}<0.05$, FDR $<0.01$, values scaled by z-score. 


\section{Cellular Physiology and Biochemistry \begin{tabular}{l|l} 
DOI: 10.1159/000492995 & (c) 2018 The Author(s). Published by S. Karger AG, Basel \\
www.karger.com/cpb
\end{tabular}

AMPK negatively regulated trophoblast invasion

When siRNA AMPKs were administered to HTR8/SVneo cells, AMPKa expression was significantly reduced by siAMPK $\alpha 1$ (Fig. $5 \mathrm{~A}$ ), AMPK knockdown and control cells were further studied using the matrigel transwell assay in the presence of AMPK specific activator AICAR or inhibitor Compound C. Either AICAR or $1 \% \mathrm{O}_{2}$ significantly suppressed HTR8 cell invasion, while siAMPK or Compound $\mathrm{C}$ treatment alone up-regulated the invasion of HTR8/SVneo cells (Fig. 5B). However, in the presence of siAMPK or Compound $C$, the inhibitory effects of AICAR or hypoxia on HTR8/SVneo cells were largely blocked. Consistent with this finding, gelatin zymography demonstrated that MMP2 activity in HTR8/SVneo cells was significantly up-regulated by siAMPK or Compound $\mathrm{C}$ treatment, but down-regulated by AICAR or $1 \% \mathrm{O}_{2}$ treatment; siAMPK or Compound $\mathrm{C}$ treatment partially rescued the inhibitory effects on MMP2 activity by AICAR or $1 \% \mathrm{O}_{2}$ (Fig. 5C). To further study the underlying regulatory mechanism of AMPK on MMP2 activity, trophoblast reactive oxygen species (ROS) generation from AMPK-promoted FA $\beta$-oxidation was determined. AICAR or $1 \% \mathrm{O}_{2}$ treatment significantly increased intracellular ROS in HTR8/SVneo cells, while etoxomir, an irreversible inhibitor of carnitine palmitoyltransferase-1 (CPT-1), totally alleviated AICAR induced ROS production (Fig. 5D). Collectively, AMPK negatively regulate trophoblast invasion by inhibiting MMP2, probably through ROS generation, indicating that hyper-activation of AMPK could be a causative factor of the impaired trophoblast invasion in PE.

\section{AMPK activation suppresses human villous outgrowth in vitro}

To validate our findings from the in vitro cell model, the effects of pharmacological modulation of AMPK on human villous explants outgrowth were evaluated. AICAR treatment $(200 \mu \mathrm{mol} / \mathrm{L})$ or $24 \mathrm{~h}$ of $1 \% \mathrm{O}_{2}$ effectively activated villous AMPK as shown by Western blotting (Fig. 6A). Consistent with this finding, either AICAR or $1 \% \mathrm{O}_{2}$ significantly compromised the outgrowth of villi explants after $24 \mathrm{~h}$, as compared to the control group (Fig. 6B). 


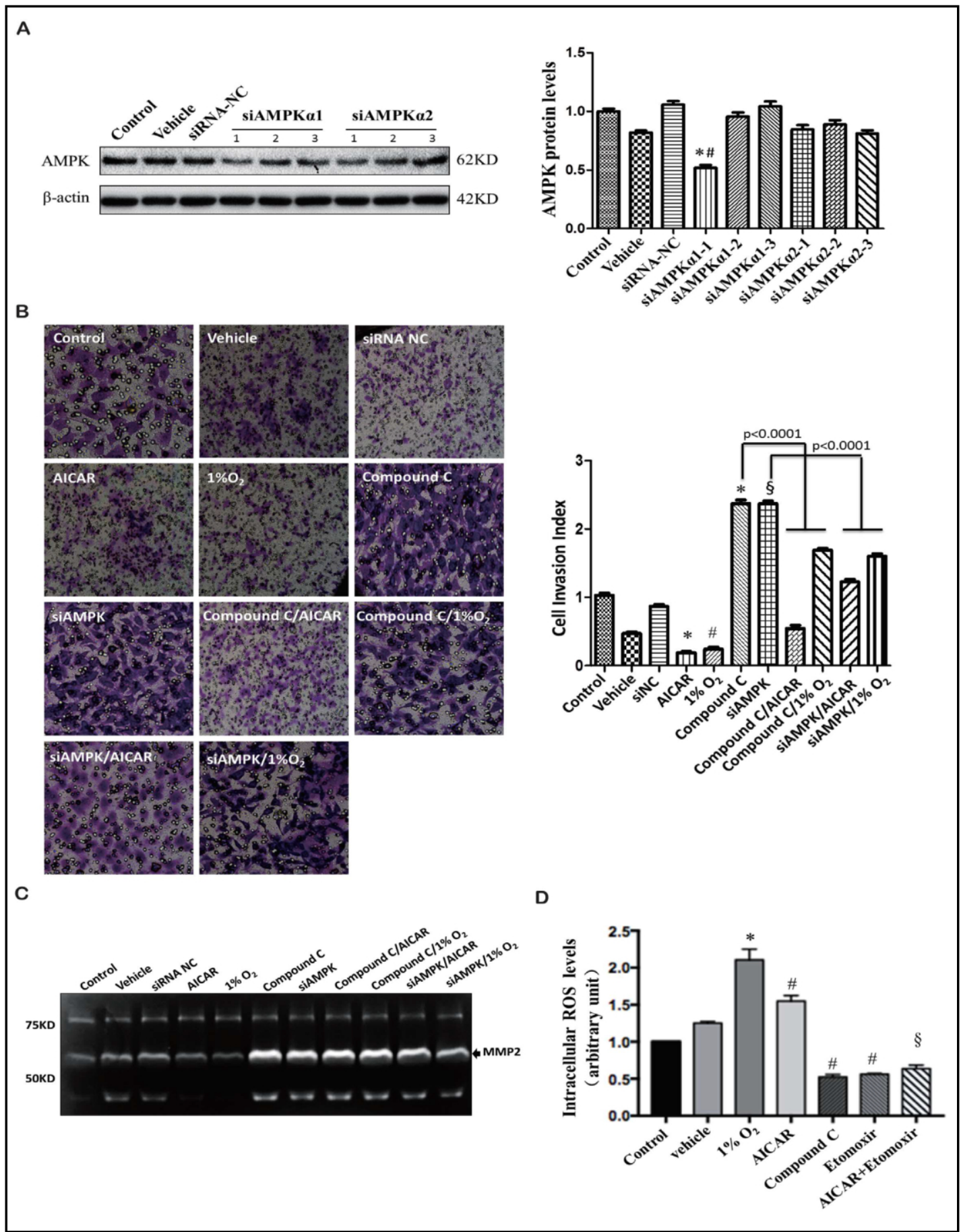

Fig. 5. The regulatory effects of AMPK on trophoblast invasion. A. AMPK protein expression normalized to $\beta$-actin in HTR8/SVneo cells after 24 h of siRNA transfection, $* \mathrm{p}<0.001$ vs. vehicle, $\# \mathrm{p}<0.001$ vs. siRNA-NC, $\mathrm{N}=3$; B. Matrigel transwell assay of HTR8/SVneo cell after $24 \mathrm{~h}$ treatments of $1 \% \mathrm{O}_{2}, 21 \% \mathrm{O}_{2}$ (control), vehicle (DMSO), $200 \mu \mathrm{mol} / \mathrm{L}$ AICAR, $\mu \mathrm{mol} / \mathrm{L}$ Compound C, siAMPK, siRNA-NC, AICAR plus Compound C, $1 \%$ $\mathrm{O}_{2}$ plus Compound $\mathrm{C}$, siAMPK plus AICAR, siAMPK plus $1 \% \mathrm{O}_{2}$ respectively. $* \mathrm{p}<0.001$ vs. vehicle, $\# \mathrm{p}<0.001$ vs. control, $\$ \mathrm{p}<0.001$ vs. siRNA-NC, N=3; C. Gelatin zymography of MMP2 in the HTR8/SVneo cells; D. Intracellular ROS in HTR8/SVneo after $24 \mathrm{~h}$ treatment of vehicle (DMSO), 1\% oxygen, 200 $\mu \mathrm{M}$ AICAR, $20 \mu \mathrm{M}$ Compound $\mathrm{C}, 25 \mu \mathrm{M}$ etomoxir, or $200 \mu \mathrm{M}$ AICAR along with $25 \mu \mathrm{M}$ etomoxir, respectively. $* \mathrm{p}<0.001$ vs. control, $\# \mathrm{p}<0.001$ vs. vehicle, $\S \mathrm{p}<0.001$ vs. AICAR, $\mathrm{N}=3$. 


\section{Cellular Physiology and Biochemistry \begin{tabular}{l|l} 
DOI: 10.1159/000492995 & $\begin{array}{l}\text { (c) } 2018 \text { The Author(s). Published by S. Karger AG, Basel } \\
\text { www.karger.com/cpb }\end{array}$
\end{tabular} \\ Yang et al:: AMPK Regulates Trophoblasts Metabolism and Invasion}

\section{Discussion}

PE has been characterized by shallow trophoblasts invasion, poor placentation, and compromised spiral artery remodeling; these features ultimately lead to a reduced uteroplacental circulation, and placental ischemia [29]. Alterations in metabolic substrates and a consequent energy crisis have been thought to trigger the clinical manifestations of PE. Although the metabolite profile of PE has been studied in various biosamples, including peripheral blood, urine and amniotic fluid [30-32], the metabolite characteristics of the placenta in PE are still largely unknown.

FA release from maternal adipose tissue is increased in the third trimester due to lipolysis [33], and FAs can be taken up by the placenta [34]. This suggests that FAs could be crucial for maintaining normal placental function. In the present study, we report the accumulation of cis double bond FAs in placentas from PE pregnancies. The classical pathway of mitochondrial-oxidation of unsaturated FAs involves cis double bonds at even-numbered $\mathrm{C}$ atoms to yield 2-trans-4-cis-intermediates, which are further reduced and isomerized by DECR1 to their respective 3-trans-intermediates [35, 36]. In contrast, trans double bond FAs are able to enter $\beta$-oxidation without being isomerized. Therefore, dysregulation of DECR1 might result in a shift of $\beta$-oxidation substrates from cis double bond FAs to trans double bond FAs. Consistent with this, two trans double bond FA were significantly decreased in PE placentas, indicating that they had been largely consumed by energy production. In addition, in contrast to the retention of long chain FAs, medium chain FAs in PE placentas were down-regulated, perhaps because they were able to freely cross mitochondrial membranes, while the long chain FAs require carnitine palmitoyl transterase- 1 (CPT-1) to facilitate transportation from cytosol to mitochondria. Taken together, our data suggest that PE placentas preferentially use FAs that can be used directly without extra modification and/or transportation steps, thus effecting a more efficient energy supply. The marked elevation in $\beta$-oxidation in PE placentas implies that FAs are crucial energy resources for trophoblast function. The role of the 'master switch of FA metabolism', AMPK, is likely to be key to the etiology of PE.

AMPK is critical for trophoblast glycolytic and mitochondrial energy resources [37]. In this study, we found that the terminal FA oxidation product, MDA, was significantly increased in PE placenta. Consistent with this finding, PE placentas demonstrated hyperphosphorylation of the AMPK-ACC signaling pathway, indicating that abnormal AMPK activation could be a causative event in the development of PE.

To further investigate the role of AMPK on trophoblastic function, an experimental model was required to mimic the metabolic changes of the placenta in PE. Although various in vitro and in vivo models have been used to study the etiology of PE[38-40], such as exposure of trophoblast cells to hypoxia and hypoxia/reoxygenation [41-44], induction of 'PE-like' trophoblast cell metabolic alterations had not previously been demonstrated. Our data show that persistent exposure to $1 \%$ oxygen for $24 \mathrm{~h}$ was required to activate AMPK in HTR8/SVneo cells, indicating that trophoblast cells were resistant to low oxygenation. 


\section{Cellular Physiology Cell Physiol Biochem 2018;49:578-594 \begin{tabular}{l|l|l} 
DOI: 10.1159/000492995 & $\begin{array}{l}\text { O } 2018 \text { The Author(s). Published by S. Karger AG, Basel } \\
\text { www.karger.com/cpb }\end{array}$
\end{tabular} \\ Yang et al.: AMPK Regulates Trophoblasts Metabolism and Invasion}

The placenta is associated with low oxygen tensions throughout pregnancy [45]; the oxygen concentration in the intervillous space increases from $2.5 \%$ at 8 weeks of pregnancy to $8.5 \%$ at 12 weeks consequent on spiral artery remodeling [46]. Since trophoblasts are exposed to physiological oxygen concentrations that are significantly lower than other cell types, the placenta has be able to fulfill its energy demand in low oxygen conditions. This may partially explain why PE placentas are able to generate an energy supply through increased FA oxidation during ischemia. However, persistent exposure of HTR8/SVneo cells to 1\% oxygen failed to demonstrate the shift of FA oxidation substrates, we then provided the evidence that DECR1, a key enzyme that catalyze the isomerization of cis double bond FA to trans double bond FA in $\beta$-oxidation, is significantly compromised in PE placentas, suggesting that the shift of $\beta$-oxidation substrate in PE placentas could be caused by limited isomerization from cis to trans double bond FA. Moreover, DECR1 is abundantly expressed in HTR8/SVneo cells compare to primary human trophoblast (PHT), indicating that HTR8/SVneo cells have much higher catalytic capability for isomerizing cis double bond FAs to trans double bond FAs than primary trophoblast. Instead of a preferential metabolism of trans double bond FAs, in HTR8/SVneo cells, hypoxia globally elevated FA metabolism; in contrast, the limited DECR1 in human PE placental trophoblasts resulted in reduced trans double bond FA formation from cis isomers - the reservoir of trans double bond FA was thus quickly depleted when $\beta$-oxidation was promoted by AMPK activation.

Due to the resistance of trophoblast to low oxygen conditions, the aberrant AMPK activation in PE placentas is less likely to be induced by insufficient energy production. The known upstream kinases which phosphorylate the activating site of AMPK at Thr172 include liver kinase B 1 (LKB1)[47], calcium-calmodulin-dependent kinase kinase $\beta$ (CaMKK $\beta$ )[48] and transforming growth factor-b-activated protein kinase-1 (TAK1). It will be interesting to further identify the causative upstream regulator of AMPK hyper-activation in PE placentas.

In addition to a pivotal regulatory function in metabolism, AMPK has been recently shown to modulate cell invasion [49]. Cell invasion is an energy consuming process, thus FA oxidation should play an important role in the regulation of trophoblast invasion due to its high efficiency in ATP production. Surprisingly, in the present study, we observed that hyper-activation of AMPK and consequent elevation in FA oxidation result in reduced trophoblast invasion. In a recent study, Yang et al. reported the inhibitory effects of FA on trophoblast invasion [50], consistent with our results. FA oxidation is the major source of reactive oxygen species (ROS), and thus aberrant elevation of FA oxidation may result in bursts of ROS generation. Our group and others have shown that oxidative stress inhibits trophoblast invasion $[44,51]$. Therefore, excessive FA oxidation may impair trophoblast invasion through ROS production. In this study, we provide evidence that, hypoxia or AICAR treatment significantly increased ROS production in HTR8/SVneo cells, while inhibition of FA $\beta$-oxidation totally diminished AICAR promoted ROS production. MMPs are known important for trophoblast invasion [52], although an inhibitory effect of AMPK on MMPs has recently been reported in endothelial progenitor cells and in human umbilical vein endothelial cells $[53,54]$, the present study is the first to demonstrate that AMPK inhibits MMP2 in trophoblast, probably by promoting ROS generation from FA $\beta$-oxidation.

We also demonstrated that modulation of AMPK activity regulated outgrowth of human first trimester villi, strongly suggesting that AMPK could be a promising interventional target for prevention and or treatment of PE. Although Banek and colleagues have shown that pharmacological activation of AMPK in the Reduced Uterine Perfusion Pressure (RUPP)-induced PE rat model ameliorates hypertension [38], the protective effects of AMPK activation on PE are probably largely derived from its regulatory function on angiogenesis rather than on trophoblast invasion. Therefore, the timing and type of AMPK modulation should be carefully tailored to the intended effect. 


\section{Cellular Physiology Cell Physiol Biochem 2018;49:578-594 \begin{tabular}{ll|l} 
and Biochemistry Published online: 29 August, 2018 & $\begin{array}{l}\text { (C) } 2018 \text { The Author(s). Published by S. Karger AG, Basel } \\
\text { www.karger.com/cpb }\end{array}$
\end{tabular}}

\section{Conclusion}

In conclusion, although the discrepancies in transcriptome and proteome between PE and normal placentas have been found previously $[55,56]$, this study is the first to report PE placentas were associated with AMPK hyper-activation and an aberrant FA metabolomic profile. Persistent low oxygen conditions were required to induce 'PE-like' metabolic features in HTR8/SVneo cells. Most importantly, AMPK activation played a negative regulatory role on trophoblast invasion as well as human villi outgrowth. It will be intriguing to further validate the therapeutic potential of AMPK in the management of PE using animal models.

\section{Acknowledgements}

We thank Dr. C.H.Graham of Queen's University, Canada, for the kind gift of HTR8/SVneo cells. In addition, this study was supported by the "111 program" of Ministry of Education P.R.C and State Administration of Foreign Experts Affairs P.R.C, and State International Collaborative Laboratory of Reproduction and Development.

This work was supported by grants from the National Natural Sciences Foundation of China (81671488 and 81871189 to C.T; 81771613 and 81520108013 to H.Q), National Health and Family Planning Commission (201402006 to H.Q), Ministry of Science and Technology (2016YFC1000407 to H.Q), Chongqing Municipal Education Commission (CXTDX201601014 to H.Q, KJ1500223 to C.T), Commission of Science and Technology of Chongqing Municipality (cstc2017jcyjBX0045 to C.T), Chongqing Entrepreneurship and Innovation Supporting Program for Returned Overseas Students (cx2017104 to C.T), and Chongqing Medical University (CYYQ201507 to C.T).

\section{Disclosure Statement}

The authors declare to have no competing interests.

\section{References}

1 Say L, Chou D, Gemmill A, Tuncalp 0, Moller AB, Daniels J, Gulmezoglu AM, Temmerman M, Alkema L: Global causes of maternal death: a WHO systematic analysis. Lancet Glob Health 2014;2:e323-333.

$\longrightarrow 2$ American College of O, Gynecologists, Task Force on Hypertension in P: Hypertension in pregnancy. Report of the American College of Obstetricians and Gynecologists' Task Force on Hypertension in Pregnancy. Obstet Gynecol 2013;122:1122-1131.

-3 Sibai BM: Diagnosis and management of gestational hypertension and preeclampsia. Obstet Gynecol 2003;102:181-192.

-4 Ghulmiyyah L, Sibai B: Maternal mortality from preeclampsia/eclampsia. Semin Perinatol 2012;36:56-59.

5 Amorim MM, Santos LC, Faundes A: Corticosteroid therapy for prevention of respiratory distress syndrome in severe preeclampsia. Am J Obstet Gynecol 1999;180:1283-1288.

-6 Conrad KP, Benyo DF: Placental cytokines and the pathogenesis of preeclampsia. Am J Reprod Immunol 1997;37:240-249.

7 Strickland S, Richards WG: Invasion of the trophoblasts. Cell 1992;71:355-357.

$>8$ Cross JC, Werb Z, Fisher SJ: Implantation and the placenta: key pieces of the development puzzle. Science 1994;266:1508-1518.

- Luo X, Cheng C, Tan Z, Li N, Tang M, Yang L, Cao Y: Emerging roles of lipid metabolism in cancer metastasis. Mol Cancer 2017;16:76.

10 Yan Y, Peng H, Wang P, Wang H, Dong M: Increased expression of fatty acid binding protein 4 in preeclamptic Placenta and its relevance to preeclampsia. Placenta 2016;39:94-100. 


\section{Cellular Physiology Cell Physiol Biochem 2018;49:578-594 and Biochemistry DOI: 10.1159/000492995 \begin{tabular}{l|l} 
O 2018 The Author(s). Published by S. Karger AG, Basel \\
wwww.kargercom/cpb
\end{tabular}

11 Ferchaud-Roucher V, Rudolph MC, Jansson T, Powell TL: Fatty acid and lipid profiles in primary human trophoblast over 90h in culture. Prostag Leukotr Ess 2017;121:14-20.

-12 Ewart MA, Kennedy S: AMPK and vasculoprotection. Pharmacol Ther 2011;131:242-253.

13 Hardie DG: Roles of the AMP-activated/SNF1 protein kinase family in the response to cellular stress. Biochem Soc Symp 1999;64:13-27.

14 Nguyen TM: Impact of 5'-amp-activated Protein Kinase on Male Gonad and Spermatozoa Functions. Front Cell Dev Biol 2017;5:25.

15 Russell RR, 3rd, Li J, Coven DL, Pypaert M, Zechner C, Palmeri M, Giordano FJ, Mu J, Birnbaum MJ, Young LH: AMP-activated protein kinase mediates ischemic glucose uptake and prevents postischemic cardiac dysfunction, apoptosis, and injury. J Clin Invest 2004;114:495-503.

-16 Lempiainen J, Finckenberg P, Levijoki J, Mervaala E: AMPK activator AICAR ameliorates ischaemia reperfusion injury in the rat kidney. Br J Pharmacol 2012;166:1905-1915.

17 Jiang T, Yu JT, Zhu XC, Zhang QQ Tan MS, Cao L, Wang HF, Shi JQ, Gao L, Qin H, Zhang YD, Tan L: Ischemic preconditioning provides neuroprotection by induction of AMP-activated protein kinase-dependent autophagy in a rat model of ischemic stroke. Mol Neurobiol 2015;51:220-229.

18 Deng Q, Chen Y, Yin N, Shan N, Luo X, Tong C, Zhang H, Baker PN, Liu X, Qi H: $\mathrm{N}$-acetylglucosaminyltransferase $\mathrm{V}$ inhibits the invasion of trophoblast cells by attenuating MMP2/9 activity in early human pregnancy. Placenta 2015;36:1291-1299.

19 Guo C, He Z, Wen L, Zhu L, Lu Y, Deng S, Yang Y, Wei Q, Yuan H: Cytoprotective effect of trolox against oxidative damage and apoptosis in the NRK-52e cells induced by melamine. Cell Biol Int 2012;36:183-188.

20 Zhao J, Xu S, Song F, Nian L, Zhou X, Wang S: 2, 3,5, 4'-tetrahydroxystilbene-2-0-beta-D-glucoside protects human umbilical vein endothelial cells against lysophosphatidylcholine-induced apoptosis by upregulating superoxide dismutase and glutathione peroxidase. IUBMB Life 2014;66:711-722.

-21 Tong C, Morrison A, Mattison S, Qian S, Bryniarski M, Rankin B, Wang J, Thomas DP, Li J: Impaired SIRT1 nucleocytoplasmic shuttling in the senescent heart during ischemic stress. FASEB J 2013;27:4332-4342.

-22 Xie B, Zhou J, Shu G, Liu DC, Zhou J, Chen J, Yuan L: Restoration of klotho gene expression induces apoptosis and autophagy in gastric cancer cells: tumor suppressive role of klotho in gastric cancer. Cancer Cell Int 2013;13:18.

23 Wang J, Tong C, Yan X, Yeung E, Gandavadi S, Hare AA, Du X, Chen Y, Xiong H, Ma C, Leng L, Young LH, Jorgensen WL, Li J, Bucala R: Limiting cardiac ischemic injury by pharmacological augmentation of macrophage migration inhibitory factor-AMP-activated protein kinase signal transduction. Circulation 2013;128:225-236.

-24 Ma H, Wang J, Thomas DP, Tong C, Leng L, Wang W, Merk M, Zierow S, Bernhagen J, Ren J, Bucala R, Li J: Impaired macrophage migration inhibitory factor-AMP-activated protein kinase activation and ischemic recovery in the senescent heart. Circulation 2010;122:282-292.

25 Fu JJ, Lin P, Lv XY, Yan XJ, Wang HX, Zhu C, Tsang BK, Yu XG, Wang H: Low molecular mass polypeptide-2 in human trophoblast: over-expression in hydatidiform moles and possible role in trophoblast cell invasion. Placenta 2009;30:305-312.

-26 Want EJ, Masson P, Michopoulos F, Wilson ID, Theodoridis G, Plumb RS, Shockcor J, Loftus N, Holmes E, Nicholson JK: Global metabolic profiling of animal and human tissues via UPLC-MS. Nat Protoc 2013;8:1732.

-27 Lorenz MA, Burant CF, Kennedy RT: Reducing time and increasing sensitivity in sample preparation for adherent mammalian cell metabolomics. Anal Chem 2011;83:3406-3414.

28 Smart KF, Aggio RB, Van Houtte JR, Villas-Boas SG: Analytical platform for metabolome analysis of microbial cells using methyl chloroformate derivatization followed by gas chromatography-mass spectrometry. Nat Protoc 2010;5:1709-1729.

29 Redman CW: Current topic: pre-eclampsia and the placenta. Placenta 1991;12:301-308.

-30 Austdal M, Skrastad RB, Gundersen AS, Austgulen R, Iversen AC, Bathen TF: Metabolomic biomarkers in serum and urine in women with preeclampsia. PloS One 2014;9:e91923.

-31 Bahado-Singh RO, Syngelaki A, Mandal R, Graham SF, Akolekar R, Han B, Bjondahl TC, Dong E, Bauer S, Alpay-Savasan Z, Turkoglu O, Ogunyemi D, Poon LC, Wishart DS, Nicolaides KH: Metabolomic determination of pathogenesis of late-onset preeclampsia. J Matern-Fetal Neo M 2017;30:658-664. 


\section{Cellular Physiology Cell Physiol Biochem 2018;49:578-594 \begin{tabular}{l|l} 
DOI: 10.1159/000492995 & O 2018 The Author(s). Published by S. Karger AG, Basel \\
www.kargercom/cpb
\end{tabular}

-32 Kuc S, Koster MP, Pennings JL, Hankemeier T, Berger R, Harms AC, Dane AD, Schielen PC, Visser GH, Vreeken RJ: Metabolomics profiling for identification of novel potential markers in early prediction of preeclampsia. PloS One 2014;9:e98540.

-33 Herrera E, Amusquivar E, Lopez-Soldado I, Ortega H: Maternal lipid metabolism and placental lipid transfer. Horm Res 2006;65:59-64.

34 Gauster M, Hiden U, Blaschitz A, Frank S, Lang U, Alvino G, Cetin I, Desoye G, Wadsack C: Dysregulation of placental endothelial lipase and lipoprotein lipase in intrauterine growth-restricted pregnancies. J Clin Endocrinol Metab 2007;92:2256-2263.

35 Luo MJ, Smeland TE, Shoukry K, Schulz H: Delta 3, 5, delta 2, 4-dienoyl-CoA isomerase from rat liver mitochondria. Purification and characterization of a new enzyme involved in the beta-oxidation of unsaturated fatty acids. J Biol Chem 1994;269:2384-2388.

-36 Koivuranta KT, Hakkola EH, Hiltunen JK: Isolation and characterization of cDNA for human 120 kDa mitochondrial 2, 4-dienoyl-coenzyme A reductase. Biochem J 1994;304:787-792.

-37 Waker CA, Albers RE, Pye RL, Doliboa SR, Wyatt CN, Brown TL, Mayes DA: AMPK Knockdown in Placental Labyrinthine Progenitor Cells Results in Restriction of Critical Energy Resources and Terminal Differentiation Failure. Stem Cells Dev 2017;26:808-817.

-38 Banek CT, Bauer AJ, Needham KM, Dreyer HC, Gilbert JS: AICAR administration ameliorates hypertension and angiogenic imbalance in a model of preeclampsia in the rat. Am J Physiol Heart Circ Physiol 2013;304:H1159-1165.

-39 Zhou CC, Zhang Y, Irani RA, Zhang H, Mi T, Popek EJ, Hicks MJ, Ramin SM, Kellems RE, Xia Y: Angiotensin receptor agonistic autoantibodies induce pre-eclampsia in pregnant mice. Nat Med 2008;14:855-862.

40 Khoo NK, Bechberger JF, Shepherd T, Bond SL, McCrae KR, Hamilton GS, Lala PK: SV40 Tag transformation of the normal invasive trophoblast results in a premalignant phenotype. I. Mechanisms responsible for hyperinvasiveness and resistance to anti-invasive action of TGFbeta. Int J Gynecol Cancer 1998;77:429-439.

-41 He G, Xu W, Chen Y, Liu X, Xi M: Abnormal apoptosis of trophoblastic cells is related to the up-regulation of CYP11A gene in placenta of preeclampsia patients. PloS One 2013;8:e59609.

42 Yang Z, Bai B, Luo X, Xiao X, Liu X, Ding Y, Zhang H, Gao L, Li J, Qi H: Downregulated Kruppel-like factor 8 is involved in decreased trophoblast invasion under hypoxia-reoxygenation conditions. Reprod Sci 2014;21:72-81.

43 Luo R, Wang Y, Xu P, Cao G, Zhao Y, Shao X, Li YX, Chang C, Peng C, Wang YL: Hypoxia-inducible miR210 contributes to preeclampsia via targeting thrombospondin type I domain containing 7A. Sci Rep 2016;6:19588.

44 Zhuang B, Luo X, Rao H, Li Q, Shan N, Liu X, Qi H: Oxidative stress-induced C/EBPbeta inhibits beta-catenin signaling molecule involving in the pathology of preeclampsia. Placenta 2015;36:839-846.

45 Hustin J, Schaaps JP: Echographic [corrected] and anatomic studies of the maternotrophoblastic border during the first trimester of pregnancy. Am J Obstet Gynecol 1987;157:162-168.

-46 Pringle KG, Kind KL, Sferruzzi-Perri AN, Thompson JG, Roberts CT: Beyond oxygen: complex regulation and activity of hypoxia inducible factors in pregnancy. Hum Reprod Update 2010;16:415-431.

\$7 Sakamoto K, Zarrinpashneh E, Budas GR, Pouleur AC, Dutta A, Prescott AR, Vanoverschelde JL, Ashworth A, Jovanovic A, Alessi DR, Bertrand L: Deficiency of LKB1 in heart prevents ischemia-mediated activation of AMPKalpha2 but not AMPKalpha1. Am J Physiol Endocrinol Metab 2006;290:E780-788.

48 Woods A, Dickerson K, Heath R, Hong SP, Momcilovic M, Johnstone SR, Carlson M, Carling D: $\mathrm{Ca}^{2}+$ / calmodulin-dependent protein kinase kinase-beta acts upstream of AMP-activated protein kinase in mammalian cells. Cell Metab 2005;2:21-33.

49 Schaffer BE, Levin RS, Hertz NT, Maures TJ, Schoof ML, Hollstein PE, Benayoun BA, Banko MR, Shaw RJ, Shokat KM, Brunet A: Identification of AMPK Phosphorylation Sites Reveals a Network of Proteins Involved in Cell Invasion and Facilitates Large-Scale Substrate Prediction. Cell Metab 2015;22:907-921.

-50 Yang C, Lim W, Bazer FW, Song G: Decanoic acid suppresses proliferation and invasiveness of human trophoblast cells by disrupting mitochondrial function. Toxicol Appl Pharmacol 2018;339:121-132.

-51 Yang C, Lim W, Bazer FW, Song G: Myricetin suppresses invasion and promotes cell death in human placental choriocarcinoma cells through induction of oxidative stress. Cancer Lett 2017;399:10-19.

-52 Fan M, Xu Y, Hong F, Gao X, Xin G, Hong H, Dong L, Zhao X: Rac1/beta-Catenin Signalling Pathway Contributes to Trophoblast Cell Invasion by Targeting Snail and MMP9. Cell Physiol Biochem 2016;38:1319-1332. 


\section{Cellular Physiology Cell Physiol Biochem 2018;49:578-594

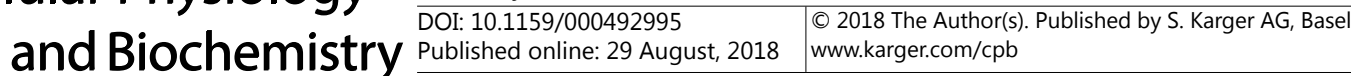

Yang et al.: AMPK Regulates Trophoblasts Metabolism and Invasion

53 Li WD, Li NP, Song DD, Rong JJ, Qian AM, Li XQ: Metformin inhibits endothelial progenitor cell migration by decreasing matrix metalloproteinases, MMP-2 and MMP-9, via the AMPK/mTOR/autophagy pathway. Int J Mol Med 2017;39:1262-1268.

54 Esfahanian N, Shakiba Y, Nikbin B, Soraya H, Maleki-Dizaji N, Ghazi-Khansari M, Garjani A: Effect of metformin on the proliferation, migration, and MMP-2 and -9 expression of human umbilical vein endothelial cells. Mol Med Rep 2012;5:1068-1074.

55 Qian Y, Lu Y, Rui C, Qian Y, Cai M, Jia R: Potential Significance of Circular RNA in Human Placental Tissue for Patients with Preeclampsia. Cell Physiol Biochem 2016;39:1380-1390.

-56 Li H, Han L, Yang Z, Huang W, Zhang X, Gu Y, Li Y, Liu X, Zhou L, Hu J, Yu M, Yang J, Li Y, Zheng Y, Guo J, Han J, Li L: Differential Proteomic Analysis of Syncytiotrophoblast Extracellular Vesicles from Early-Onset Severe Preeclampsia, using 8-Plex iTRAQ Labeling Coupled with 2D Nano LC-MS/MS. Cell Physiol Biochem 2015;36:1116-1130. 